\title{
Clinical Impact of Ventilation Duration in Patients with Stroke Undergoing Interventional Treatment under General Anesthesia: The Shorter the Better?
}

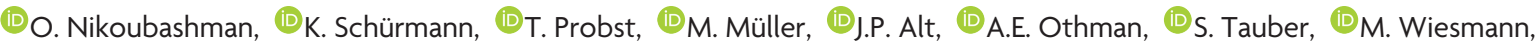
and (1D. A. Reich

\begin{abstract}
BACKGROUND AND PURPOSE: Whether general anesthesia for neurothrombectomy in patients with ischemic stroke has a negative impact on clinical outcome is currently under discussion. We investigated the impact of early extubation and ventilation duration in a cohort that underwent thrombectomy under general anesthesia.
\end{abstract}

MATERIALS AND METHODS: We analyzed 103 consecutive patients from a prospective stroke registry. They met the following criteria: CTA-proved large-vessel occlusion in the anterior circulation, ASPECTS above 6 on presenting cranial CT, revascularization by thrombectomy with the patient under general anesthesia within 6 hours after onset of symptoms, and available functional outcome (mRS) 90 days after onset.

RESULTS: The mean ventilation time was $128.07 \pm 265.51$ hours (median, 18.5 hours; range, 1-1244.7 hours). Prolonged ventilation was associated with pneumonia during hospitalization and unfavorable functional outcome (mRS $\geq 3$ ) and death at follow-up (Mann-Whitney $U$ test; $P \leq .001)$. According to receiver operating characteristic analysis, a cutoff after 24 hours predicted unfavorable functional outcome with a sensitivity and specificity of $60 \%$ and $78 \%$, respectively. Our results imply that delayed extubation was not associated with a less favorable clinical outcome compared with immediate extubation after the procedure.

CONCLUSIONS: Short ventilation times are associated with a lower pneumonia rate and more favorable clinical outcome. Cautious interpretation of our data implies that whether patients are extubated immediately after the procedure is irrelevant for clinical outcome as long as ventilation does not exceed 24 hours.

ABBREVIATION: GA = general anesthesia

$\mathbf{R}$ ecently, 5 prospective, randomized, open-label, blinded end point-designed clinical trials have established endovascular thrombectomy as the preferred treatment technique for acute ischemic stroke caused by large-vessel occlusion. ${ }^{1-5}$ These studies showed that endovascular recanalization in the anterior circulation 6-8 hours after stroke onset is associated with favorable functional outcome in $33 \%-60 \%$ of cases (mRS $\leq 2$ at day 90 ). ${ }^{1-5}$ Basic cornerstones of the procedures such as the use of modern stent retrievers were comparable in the different studies. One con-

Received September 17, 2015; accepted after revision November 18

From the Departments of Neuroradiology (O.N., T.P., M.M., J.P.A., M.W.) and Neurology (K.S., S.T., A.R.), University Hospital Aachen, Aachen, Germany; Institute of Neuroscience and Medicine 4 (O.N.), Forschungszentrum Jülich, Jülich, Germany; and Department of Radiology (A.E.O.), University Hospital Tübingen, Tübingen, Germany.

Please address correspondence to Omid Nikoubashman, MD, Klinik für Neuroradiologie, Universitätsklinikum Aachen, Pauwelsstr 30, 52074 Aachen, Germany;

e-mail: onikoubashman@ukaachen.de

= Indicates article with supplemental on-line tables.

http://dx.doi.org/10.3174/ajnr.A4680 troversial difference, however, was the use of intubation and general anesthesia (GA) during the procedures. ${ }^{1-5}$ In fact, GA rates ranged from $6.7 \%$ to $37.8 \%$ in the mentioned prospective studies. ${ }^{1-5}$ Most active members of the Society of Vascular and Interventional Neurology stated, in a recent survey, that they preferred general anesthesia over conscious sedation for recanalization treatment of acute ischemic stroke. ${ }^{6}$ Patients with stroke are often noncompliant during endovascular procedures. ${ }^{6}$ Conscious sedation and local anesthesia do not immobilize agitated patients and are not apt to secure the patient's airway and thus may lead to aspiration. ${ }^{6,7}$ General anesthesia and intubation, however, allow complete immobilization and comfort of the patient, thereby allowing better image quality. ${ }^{7,8}$ On the other hand, it is assumed that delays in door-to-puncture time, development of ventilatorassociated pneumonia, and ventilation-induced hypotension and hypocapnia may negatively influence clinical outcome in patients treated under GA. ${ }^{9,10}$ In a recent retrospective study $>500$ patients who were treated under GA were matched with patients treated under conscious sedation. ${ }^{11}$ Patients with GA were found 
to have a higher in-hospital mortality and higher rate of pneumonia. ${ }^{11}$ However, patients were not matched for stroke severity (NIHSS scores were not reported), and this omission could account for the worse outcome. ${ }^{11,12}$

In the end, one can break the debate down to the following 2 questions: 1) Is GA per se a risk factor for unfavorable clinical outcome? 2) Are prolonged ventilation times associated with unfavorable clinical outcome? Only a prospective, randomized study can address the first question. The second question, however, can be approached by examining a cohort that was treated predominantly under GA. Given that this was the case in the patients treated in our institution, our aim was to determine whether short ventilation times and early extubation in the angiography suite are associated with a more favorable clinical outcome.

\section{MATERIALS AND METHODS \\ Patients}

Our analysis was based on a prospective observational registry of all consecutive patients of the RWTH University Hospital Aachen (Germany) tertiary stroke center who had undergone endovascular recanalization of acute ischemic stroke in the anterior circulation since February 2010. Between February 2010 and January 2015, 318 patients with acute ischemic stroke underwent endovascular treatment for large-vessel occlusion in the anterior circulation. One hundred twenty-five patients (39.3\%) met the inclusion criteria of revascularization within 6 hours after onset of symptoms, ASPECTS above 6 on presenting cranial CT, and CTA-proved large-vessel occlusion in the anterior circulation (the distal intracranial internal carotid artery including carotid $\mathrm{T}$ and $\mathrm{M} 1 \pm \mathrm{M} 2$ segments of the middle cerebral artery). In 22 patients (17.4\%), the clinical end point (mRS 90 days after onset) could not be evaluated. Thus, 103 patients were included in our analysis.

\section{Procedures}

Standard endovascular treatment with and without stent retrievers was performed as reported previously. ${ }^{13}$ Interventionalists with an individual annual experience of at least 15-20 thrombectomies in large-vessel-occlusion acute ischemic stroke performed the interventions. The anesthesiologic and postinterventional workflow was as follows: The anesthesiologist in charge is always informed when a stroke is announced. An emergency anesthesiologic team is present in the angiography suite when a patient is moved from the CT to the angiography suite. Induction of GA and puncture of the groin are performed simultaneously whenever possible.

The type of anesthesia and the choice of medication were at the discretion of the treating anesthesiologist. Usually, after the airway was secured with a rapid-sequence intubation, general anesthesia was maintained with intravenous anesthetics such as propofol and remifentanil. A moderate hypertension (systolic blood pressure, 140-160 mm Hg) was induced until revascularization was achieved to improve cerebral perfusion. ${ }^{7}$ After revascularization was achieved, normotension (systolic pressure, 110$130 \mathrm{~mm} \mathrm{Hg}$ ) was restored to reduce the risk of reperfusion injury. ${ }^{14}$

After the procedure, patients were extubated in the angiogra- phy suite or after postinterventional CT whenever possible. Postacute work-up and treatment were performed in a certified stroke unit or neurologic intensive care unit. Criteria for extubation followed general guidelines for discontinuation of ventilatory support. ${ }^{15}$ These criteria comprised end of sedation and/or reversal of the underlying cause of respiratory failure, sufficient oxygenation $\left(\mathrm{PaO}_{2} /\right.$ fraction of inspired oxygen $\geq 120-150$ or saturation of peripheral oxygen $\geq 90 \%$ on fraction of inspired oxygen $\leq 40 \%$ and positive end-expiratory pressure $\leq 5[-8] \mathrm{cm} \mathrm{H}_{2} \mathrm{O}, \mathrm{pH}>7.25$ ), hemodynamic stability (no or low-dose vasopressor medications), ability to initiate an inspiratory effort, hemoglobin $\geq 7-10$ $\mathrm{mg} / \mathrm{dL}$, core temperature $\left(>36.0\right.$ and $\left.\leq 38-38.5^{\circ} \mathrm{C}\right)$, and mental status (awake/alert or easily arousable). Not all criteria were mandatory. In our cohort, neurologic deficits, especially those associated with increased risk of pneumonia (ie, dysphagia) and diminished respiratory drive (ie, decreased vigilance); neurologic prognosis; anticipated treatment options (ie, early carotid endarteriectomy; early hemicraniectomy; conservative treatment of raised intracranial pressure); and overall treatment concept after intervention (curative versus palliative) influenced individual decisions for extubation. Withdrawal of care was always based on a consensus of the treating medical team, considering the patient's individual medical situation, prognosis, and putative wish. In case of ambiguous situations, our institution offered support by a palliative care team and/or ethical committee.

\section{Clinical and Radiologic Data}

After obtaining permission from our local ethics board, we assessed demographics (age, sex), clinical presentation (NIHSS), disability (mRS) at admission and disability at follow-up (mRS at discharge and day 90), cerebrovascular risk factors and primary and secondary prophylactic use of antiplatelet/-coagulant medication, serum glucose level (admission), and ischemic stroke etiology (adapted from the Trial of ORG 10172 in Acute Stroke Treatment, TOAST). ${ }^{16}$ Radiologic data were assessed by the primary treating neuroradiologist and re-evaluated by a blinded colleague. A reference standard was established for statistical analyses in a consensus reading for cases in which there was disagreement. Radiologic and procedural data comprised initial and postinterventional/follow-up imaging for the site of large-vessel occlusion and the extent of initial and final ischemic changes (ASPECTS), time from onset of symptoms to imaging and beginning of treatment, type of intra-arterial treatment (including bridging therapy) and devices, procedural time intervals, result of recanalization (TICI), and peri- and posttreatment complications (hemorrhagic and local events, secondary hemicraniectomy). ${ }^{17}$ Hemorrhagic events were reported according to the European Cooperative Acute Stroke Study (ECASS) definition. ${ }^{18}$ The most common definition of ventilator-associated pneumonia requires pneumonia occurring 48 hours after intubation and new or progressive and persistent infiltrates on a chest radiograph plus 2 of the following: abnormal white blood cell count $(<4000$ white blood cells $/ \mathrm{mL}$ or $>12,000$ white blood cells $/ \mathrm{mL}$ ), the presence of hypothermia or fever $\left(<36^{\circ} \mathrm{C}\right.$ or $\left.>38^{\circ} \mathrm{C}\right)$, purulent sputum, and deterioration in gas exchange. ${ }^{19}$ The role of chest radiographs in the diagnosis of pneumonia, however, has been discussed controversially, because the sensitivity of chest radiographs for the de- 
tection of infiltrates is poor. ${ }^{20}$ Therefore, we chose a more pragmatic approach in daily clinical care and treated all patients with clinical and laboratory and/or radiologic examinations suggestive of pneumonia. Accordingly, we chose to include these patients in our pneumonia analysis and to rather overestimate than underestimate pneumonia rates.

Primary outcome measures were the occurrence of ventilatorassociated pneumonia during hospitalization, functional outcome defined as an mRS of $\leq 2$, and mortality on follow-up after 90 days.

\section{Statistical Analysis}

We used the Student $t$, Mann-Whitney $U$, Pearson $\chi^{2}$, and Fisher exact tests, depending on the type of data and data distribution. Binary logistic regression and Cox regression were used for multivariate analyses. Receiver operating characteristics were used for threshold estimation. $P$ values under the $\alpha$ level of .05 were significant. All statistical analyses were performed with SPSS 23 software (IBM, Armonk, New York).

\section{RESULTS \\ Clinical Data}

Revascularization was successful in 90/99 (90.9\%) procedures that involved mechanical stent-assisted thrombectomy. On average, 2.4 stent-retriever passes were needed for vessel recanalization. There were 4 cases of procedure-related intracranial SAH caused by vessel perforation, with consecutive parenchymal hemorrhage (ECASS-PH2) in 2 of these 4 cases. The rate of intracranial bleeding ( $\mathrm{SAH}$ and $\mathrm{PH} 2$ ), which included all postinterventional imaging results regardless of cause and clinical impact, was $7.8 \%(8 / 103)$. The rate of symptomatic intracranial hemorrhages was $4.8 \%(5 / 103)$.

Forty of 42 patients in whom pneumonia was suspected underwent chest radiography. Thirty of these 40 (75\%) patients had pathologic chest radiographs and $\geq 2$ clinical and/or laboratory criteria for pneumonia. Chest radiographs were not conclusive in the remaining 10 patients. Clinical and laboratory criteria were highly suggestive of pneumonia in 8 of these 10 patients. All 8 patients received antibiotic treatment for suspected pneumonia. Accordingly, we classified these 8 patients as pneumonia cases. In the remaining 2 of 10 patients with nonconclusive chest radiographs, clinical and laboratory examinations eventually did not confirm the suspected diagnosis of pneumonia. Hence, these patients were not classified as having pneumonia. A chest radiograph was not performed due to palliative management in 2 patients, in whom pneumonia was suspected. Both patients died due to multiorgan failure when intensive care measures were terminated according to the patients' wishes. One patient who was treated for pneumonia and died 4 days after admission was included in our pneumonia calculation. The other patient died within 36 hours after admission before the suspected diagnosis of pneumonia could have been proved or disproved. This patient was not classified as a ventilator-associated pneumonia case. In summary, there were 39 cases of ventilator-associated pneumonia, which included 9 (23\%) cases of pneumonia-associated sepsis. Diagnoses were based on clinical, laboratory, and radiologic findings in $30(77 \%)$ cases and on clinical and laboratory examinations alone in 9 cases $(23 \%)$.

The end point of death at 3 months showed a marked nonnormal distribution, with $50 \%$ of deaths occurring within 3 days and $75 \%$ of deaths occurring within 2 weeks after treatment (mean, $11.0 \pm 18.3$ days; range, $0-75$ days). Early death was primarily attributed to secondary complications due to unsuccessful stroke treatment and consecutive switch to palliative care. Causes of death were cerebrovascular complications ( 12 cases), sepsis due to pneumonia (3 cases), respiratory failure due to pneumonia ( 3 cases), cardiac causes ( 4 cases), competing causes ( 4 cases), and unknown (2 cases).

\section{Anesthesia}

An overview of clinical, radiologic, and procedural characteristics can be found in On-line Table 1. All patients received intra-arterial treatment under general anesthesia. Intubation was performed immediately before or simultaneous with the initiation of endovascular therapy in 98 of 103 (95.1\%) patients. The remaining 5 patients were intubated by the emergency physician on the way to our hospital. Extubation within 24 hours after interventional therapy was achieved in 58 of 103 (56.3\%) patients. This included 30 patients $(29.1 \%)$ who were extubated immediately after the procedure. Mean ventilation time of these 30 patients was $2.77 \pm 1.43$ hours (median, 2.5 hours; range, $1-6$ hours). The Table shows the impact of various clinical and procedural factors on pneumonia rates and morbidity and mortality. Prolonged ventilation was associated with pneumonia during hospitalization and unfavorable functional outcome $(m R S \geq 3)$ and death at follow-up (Mann-Whitney $U$ test; $P \leq .001$ ) (Figs 1 and 2 and Online Table 2). Linear regression analysis was not possible due to the non-normal distribution of our data. Results of binary logistic regression analyses for various ventilation cutoffs are found in On-line Table 2. Cox regression implied that pneumonia rates, morbidity, and mortality did not depend on the respective covariants (Table) $(P \geq .052)$. Receiver operating characteristic analysis implied that a cutoff after 24 hours correlated fairly well (area under the curve, 0.704) with favorable functional outcome (mRS $\leq 2$ ) (sensitivity, 60\%; specificity, 78\%). Delayed extubation compared with extubation immediately after the procedure was associated with increased pneumonia rates and unfavorable clinical outcome (Fig 3). Univariate and multivariate analyses, however, implied that the impact of delayed extubation on pneumonia rates and clinical outcome was not significant (On-line Tables 3 and 4). Only when our dataset was artificially doubled did our data show that delayed extubation after 24 hours was associated with a less favorable clinical outcome compared with immediate extubation after the procedure (On-line Table 3 ).

\section{DISCUSSION}

\section{General Anesthesia in Interventional Stroke Treatment}

Whether general anesthesia for neurothrombectomy in patients with ischemic stroke has a negative impact on clinical outcome is currently under discussion. When we established interventional thrombectomy treatment for large-vessel occlusion, we had better experience with intubation and general anesthesia than with conscious sedation in terms of safe procedural performance and com- 
Univariate analysis (Pearson $\chi^{2}$ and Student $t$ tests) of factors influencing pneumonia rates and clinical outcome

\begin{tabular}{lccc}
\multicolumn{1}{c}{ Characteristics } & $\begin{array}{c}\text { Pneumonia } \\
(\boldsymbol{P} \text { Value })\end{array}$ & $\begin{array}{c}\text { mRS }>\mathbf{2} \\
(\boldsymbol{P} \text { Value })\end{array}$ & $\begin{array}{c}\text { Death } \\
(\boldsymbol{P} \text { Value })\end{array}$ \\
\hline Hypertension & .919 & .565 & .195 \\
Diabetes & .364 & $.001^{\mathrm{a}}$ & $.001^{\mathrm{a}}$ \\
Fat metabolism disorder & .061 & .834 & .542 \\
Adiposity & .069 & .775 & .921 \\
Nicotine & .645 & $.001^{\mathrm{a}}$ & .239 \\
Alcohol & .145 & .354 & .283 \\
Cardiovascular disease & .709 & .708 & .783 \\
Atrial fibrillation & .404 & .215 & .667 \\
Prior stroke & .727 & .078 & .070 \\
Age older than 70 yr & .260 & $<.001^{\mathrm{a}}$ & .079 \\
Antiplatelet medication & .170 & .599 & .761 \\
Anticoagulant medication & .206 & .755 & .815 \\
Onset to recanalization & .268 & .630 & .884 \\
TICl $\geq 2 b$ & .947 & .237 & .059 \\
>l/3 MCA territory & $.004^{\mathrm{a}}$ & $<.001^{\mathrm{a}}$ & $<.001^{\mathrm{a}}$ \\
Pneumonia & - & $.001^{\mathrm{a}}$ & .274 \\
Intracerebral hemorrhage & .450 & .170 & .092 \\
\hline
\end{tabular}

a Significant.

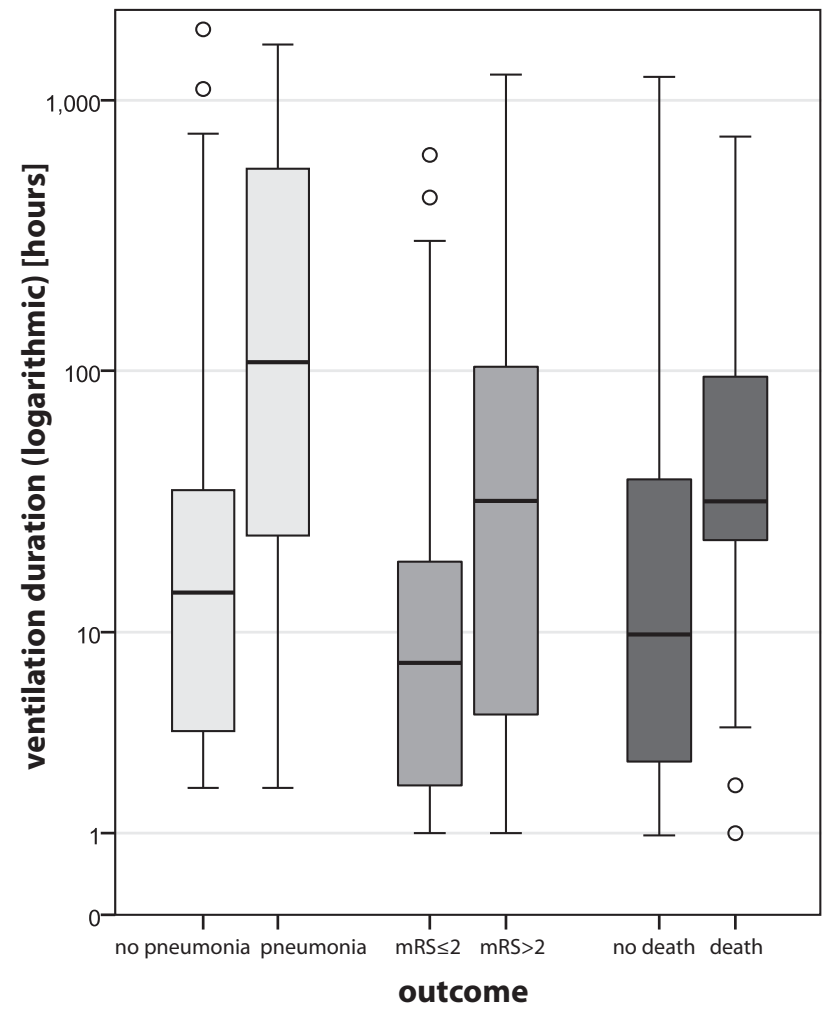

FIG 1. Boxplots illustrating the association between outcome measures and ventilation times. Clinical measures (mRS and death) as assessed after 90 days.

fort of the patient. Even though these advantages come at the price of a considerable pneumonia rate of $38 \%$, we produced satisfactory results with regard to clinical outcome and standard procedural time intervals by establishing an optimized setting with parallel instead of serial anesthesiologic and neuroradiologic workflow. ${ }^{1-5}$ Mean procedure times were significantly shorter than procedure times during conscious sedation as calculated by Brinjikji et $\mathrm{al}^{12}$ in their meta-analysis of 9 studies that deal with GA versus conscious sedation (mean time to groin, 117 minutes; mean procedural time, 89 minutes $)(P<.001$, Student $t$ test $)$.
Considering that our patient cohort was older than that in the prospective, randomized, open-label, blinded end point studies, our favorable functional outcome rate (mRS $\leq 2$ ) of $40.8 \%$ compared reasonably well with the average rate of $52.1 \%$ in the prospective, randomized, open-label, blinded end point studies. ${ }^{1-5}$ In fact, when our cohort was adjusted for comparable age (younger than 70 years), favorable functional outcome ( $\mathrm{mRS} \leq 2)$ was achieved in $66.7 \%$ of cases, which is comparable with the rate of $65 \%$ reported by Berkhemer et $\mathrm{al}^{5}$ in the Solitaire with the Intention for Thrombectomy as Primary Endovascular Treatment for Acute Ischemic Stroke study (GA rate of 36\%). Our results are also in accordance with results from a meta-analysis by Brinjikji et al. ${ }^{12}$ The authors reported that differences between patients treated under GA and those under conscious sedation in functional outcome (defined as mRS $\leq 2$ ), mortality, and respiratory complications were not significant after adjusting for stroke severity (NIHSS on symptom-onset). ${ }^{12}$ Furthermore, the authors did not find statistically significant differences in mean time to groin, mean procedural time, and time from symptom onset to revascularization between patients with GA and conscious sedation. ${ }^{12}$ In the end, the nature of our data does not allow determining the influence of GA on clinical outcome. Nevertheless, our everyday practice showed that routinely applied general anesthesia produces comparative results with regard to procedural and clinical outcome.

\section{Ventilation Duration and Clinical Outcome}

To the best of our knowledge, the question of whether short ventilation times and early extubation after neurointerventional stroke treatment are associated with a more favorable clinical outcome has not been addressed. In fact, longer ventilation times were associated with higher pneumonia rates, less favorable functional outcome, and higher mortality rates (Figs 1 and 2, and On-line Table 2). Hence, our results support the hypothesis that shorter ventilation times are associated with lower pneumonia rates and a more favorable clinical outcome. ${ }^{21-23}$ When we investigated the influence of ventilation times via various cutoffs, multivariate analyses indicated that longer ventilation times resulted in higher pneumonia rates, regardless of the time of cutoff (Online Table 2). However, multivariate analysis also indicated that longer ventilation times per se had no independent impact on unfavorable functional outcome $(P \geq .075)$. With regard to mortality, only a cutoff after 24 hours discriminated between favorable and unfavorable outcome $(P=.020$, On-line Table 2$)$. This result, which implies that ventilation duration does not affect clinical outcome, is counterintuitive because it would imply that clinical outcome did not depend on whether a patient was ventilated for 3 hours or 300 hours. Nonetheless, this finding would support the hypothesis that intubation per se has a negative impact on clinical outcome. However, data from the literature and a more elaborate interpretation of our results imply that ventilation duration may nevertheless have an impact on clinical outcome. ${ }^{8,9,21,23}$ A more thorough insight into our data shows that the missing significance at early and late cutoffs may be partly attributed to the non-normal distribution of our data. In fact, 33 of $42(78.6 \%)$ patients with favorable functional outcome were ventilated for $\leq 24$ hours and only 3 of 42 (7.1\%) patients with 


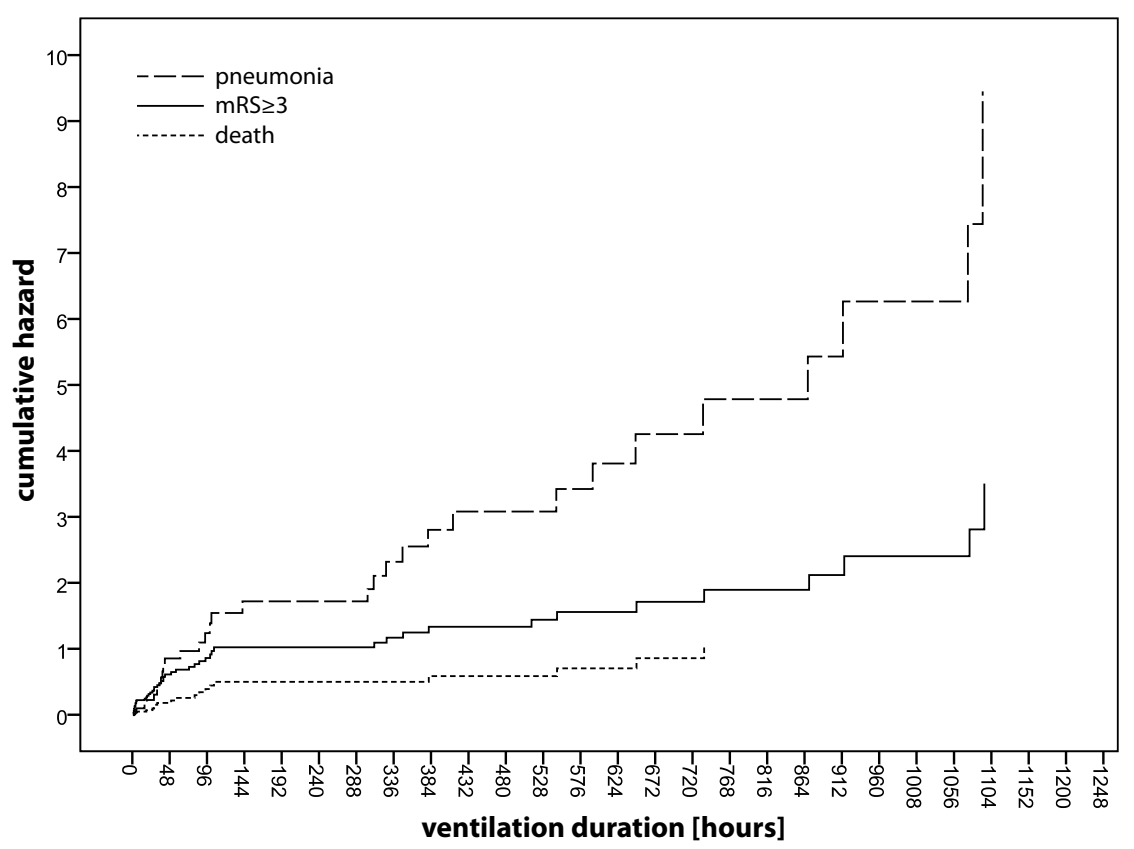

FIG 2. Cox regression showing the cumulative hazard for pneumonia during hospitalization and unfavorable clinical outcome ( $\mathrm{mRS} \geq 3$ and death assessed after 90 days), depending on ventilation duration.

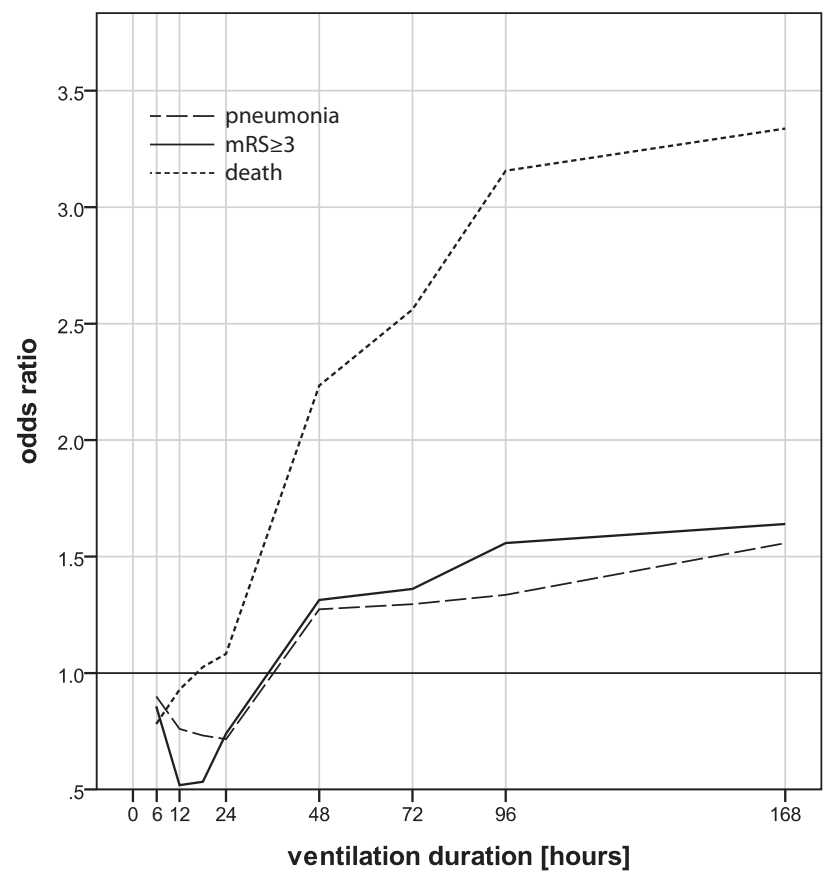

FIG 3. Odds ratios for pneumonia during hospitalization and unfavorable clinical outcome ( $m R S \geq 3$ and death assessed after 90 days), depending on whether extubation was performed immediately after the procedure or within time windows of $6,12,18.5,24,48,72,96$ hours, and 1 week.

favorable clinical outcome were ventilated for $>1$ week. Consequently, early cutoffs that result in cohorts with equal numbers of patients with favorable or unfavorable outcomes are likely to become nonsignificant. In addition, ventilation time is not an independent variable because it is always the aim to extubate as soon as possible. Accordingly, multivariate analysis revealed that clinical factors such as age $(P=.001)$, infarction size $(P \leq .013)$, and pneumonia $(P \leq .041)$, which is again strongly related to ventilation duration, have the most important impact on functional outcome (On-line Table 2). Hence, in simple terms, our results reflect that long-term ventilation is associated with a less favorable clinical course, even though the difference between cause and effect is not always clear. Nonetheless, our results may serve as a first guide to estimating the clinical prognosis of ventilated patients.

\section{Immediate versus Delayed Extubation}

It has been shown that longer duration of ventilation increases the risk of ventilator-associated pneumonia. ${ }^{21,24}$ Thus, we always attempt to extubate patients immediately after the procedure to reduce the risk of pneumonia and to assess an early neurologic status. ${ }^{23}$ However, sometimes extubation may be delayed due to medical (eg, dysphagia, low pharyngeal muscle tone, and impaired cooperation or level of consciousness; see the "Materials and Methods" section for further extubation criteria) or nonmedical reasons (eg, reduced staff capacities due to other medical emergencies). Therefore, we investigated whether delayed extubation (outside the angiography suite) was associated with a higher pneumonia rate and a less favorable clinical outcome. In fact, the longer extubation was delayed, the more patients experienced ventilator-associated pneumonia. In addition, odds ratios for death (90 days) tripled and odds ratios for unfavorable functional outcome (90 days) doubled when patients were not extubated immediately after the procedure but within 1 week (Fig 3 and On-line Table 4). However, these effects failed to reach statistical significance in multivariate analysis (On-line Tables 3 and 4). Thus, strict interpretation of our data implies that delayed extubation within 1 week had no impact on pneumonia rates and clinical outcome. However, Cox regression and Mann-Whitney $U$ tests showed that long ventilation was indeed associated with higher pneumonia rates and unfavorable outcome (Figs 1 and 2). Hence, our own results and data from the literature contradict the above-mentioned hypothesis to some extent. ${ }^{8,9,21,23}$ In summary, our results support the hypothesis that intubation per se is a risk factor for pneumonia and unfavorable clinical outcome. Nonetheless, our results are possibly also affected by the small sample size and the non-normal distribution of our data. In fact, when we artificially doubled our sample size, it became apparent that our sample size was too small for the Pearson $\chi^{2}$ test to reveal statistical significances at cutoffs after 48 hours. In the end, cautious interpretation of our data indicates that extubation immediately after the procedure does not necessarily have an impact on clinical outcome, as long as patients are extubated within 24 hours (Fig 3 and On-line Table 3). 


\section{Limitations}

The major limitation of our study is the relatively small sample size and the retrospective approach, both of which provoke speculative interpretation of our data to some extent. Nevertheless, our results may serve as a cornerstone for future multicenter studies and may be useful for centers where GA is the first choice or for patients in whom GA cannot be avoided.

\section{CONCLUSIONS}

Short ventilation times are associated with a lower pneumonia rate and more favorable clinical outcome. Cautious interpretation of our data implies that whether patients are extubated immediately after the procedure is irrelevant for pneumonia rates and clinical outcome, as long as ventilation does not exceed 24 hours.

Disclosures: Martin Wiesmann—UNRELATED: Consultancy: Stryker Neurovascular, Silk Road Medical; Grants/Grants Pending: Siemens*; Payment for Lectures (including service on Speakers Bureaus): Bracco, Covidien, Siemens, Stryker Neurovascular; Payment for Development of Educational Presentations: Abbott, ${ }^{\star}$ ab medica, ${ }^{*}$ Acandis, ${ }^{*}$ Bayer HealthCare, ${ }^{*}$ Bracco, ${ }^{*}$ B. Braun, ${ }^{*}$ Codman Neurovascular, ${ }^{*}$ Covidien, ${ }^{*}$ Dahlhausen, ${ }^{*}$ MicroVention, ${ }^{*}$ Penumbra, ${ }^{*}$ phenox, ${ }^{*}$ Philips Healthcare, ${ }^{*}$ Siemens, ${ }^{*}$ Silk Road Medical, ${ }^{*}$ St. Jude, ${ }^{*}$ Stryker Neurovascular. ${ }^{*}$ "Money paid to the institution.

\section{REFERENCES}

1. Saver JL, Goyal M, Bonafe A, et al; SWIFT PRIME Investigators. Stent-retriever thrombectomy after intravenous t-PA vs. t-PA alone in stroke. $N$ Engl J Med 2015;372:2285-95 CrossRef Medline

2. Jovin TG, Chamorro A, Cobo E, et al; REVASCAT Trial Investigators. Thrombectomy within $\mathbf{8}$ hours after symptom onset in ischemic stroke. N Engl J Med 2015;372:2296-306 CrossRef Medline

3. Goyal M, Demchuk AM, Menon BK, et al; ESCAPE Trial Investigators. Randomized assessment of rapid endovascular treatment of ischemic stroke. N Engl J Med 2015;372:1019-30 CrossRef Medline

4. Campbell BC, Mitchell PJ, Kleinig TJ, et al; EXTEND-IA Investigators. Endovascular therapy for ischemic stroke with perfusion-imaging selection. $N$ Engl J Med 2015;372:1009-18 CrossRef Medline

5. Berkhemer OA, Fransen PS, Beumer D, et al. A randomized trial of intraarterial treatment for acute ischemic stroke. N Engl J Med 2015; 372:11-20 CrossRef Medline

6. McDonagh DL, Olson DM, Kalia JS, et al. Anesthesia and sedation practices among neurointerventionalists during acute ischemic stroke endovascular therapy. Front Neurol 2010;1:118 CrossRef Medline

7. Brekenfeld C, Mattle HP, Schroth G. General is better than local anesthesia during endovascular procedures. Stroke 2010;41: 2716-17 CrossRef Medline

8. Froehler MT, Fifi JT, Majid A, et al. Anesthesia for endovascular treatment of acute ischemic stroke. Neurology 2012;79:\$167-73 CrossRef Medline

9. Takahashi C, Liang CW, Liebeskind DS, et al. To tube or not to tube?
The role of intubation during stroke thrombectomy. Front Neurol 2014;5:170 CrossRef Medline

10. Hassan AE, Chaudhry SA, Zacharatos $\mathrm{H}$, et al. Increased rate of aspiration pneumonia and poor discharge outcome among acute ischemic stroke patients following intubation for endovascular treatment. Neurocrit Care 2012;16:246-50 CrossRef Medline

11. McDonald JS, Brinjikji W, Rabinstein AA, et al. Conscious sedation versus general anaesthesia during mechanical thrombectomy for stroke: a propensity score analysis. J Neurointerv Surg 2015;7: 789-94 CrossRef Medline

12. Brinjikji W, Murad MH, Rabinstein AA, et al. Conscious sedation versus general anesthesia during endovascular acute ischemic stroke treatment: a systematic review and meta-analysis. AJNR AmJ Neuroradiol 2015;36:525-29 CrossRef Medline

13. Nikoubashman O, Reich A, Pjontek R, et al. Postinterventional subarachnoid haemorrhage after endovascular stroke treatment with stent retrievers. Neuroradiology 2014;56:1087-96 CrossRef Medline

14. Nour M, Scalzo F, Liebeskind DS. Ischemia-reperfusion injury in stroke. Interv Neurol 2013;1:185-99 CrossRef Medline

15. MacIntyre NR, Cook DJ, Ely EW Jr, et al; American College of Chest Physicians, American Association for Respiratory Care, American College of Critical Care Medicine. Evidence-based guidelines for weaning and discontinuing ventilatory support: a collective task force facilitated by the American College of Chest Physicians, the American Association for Respiratory Care, and the American College of Critical Care Medicine. Chest 2001;120:375S-95S CrossRef Medline

16. Adams HP Jr, Bendixen BH, Kappelle LJ, et al. Classification of subtype of acute ischemic stroke: definitions for use in a multicenter clinical trial-TOAST. Trial of Org 10172 in Acute Stroke Treatment. Stroke 1993;24:35-41 CrossRef Medline

17. Fugate JE, Klunder AM, Kallmes DF. What is meant by “TICI”? AJNR Am J Neuroradiol 2013;34:1792-97 CrossRef Medline

18. Trouillas $P$, von Kummer R. Classification and pathogenesis of cerebral hemorrhages after thrombolysis in ischemic stroke. Stroke 2006;37:556-61 CrossRef Medline

19. Muscedere J, Sinuff T, Heyland DK, et al; Canadian Critical Care Trials Group. The clinical impact and preventability of ventilatorassociated conditions in critically ill patients who are mechanically ventilated. Chest 2013;144:1453-60 CrossRef Medline

20. Esayag Y, Nikitin I, Bar-Ziv J, et al. Diagnostic value of chest radiographs in bedridden patients suspected of having pneumonia. Am J Med 2010;123:88.e1-5 CrossRef Medline

21. Byers JF, Sole ML. Analysis of factors related to the development of ventilator-associated pneumonia: use of existing databases. $\mathrm{Am} \mathrm{J}$ Crit Care 2000;9:344-49; quiz 351 Medline

22. Kasuya Y, Hargett JL, Lenhardt R, et al. Ventilator-associated pneumonia in critically ill stroke patients: frequency, risk factors, and outcomes. J Crit Care 2011;26:273-79 CrossRef Medline

23. Talke PO, Sharma D, Heyer EJ, et al. Republished: Society for Neuroscience in Anesthesiology and Critical Care expert consensus statement-anesthetic management of endovascular treatment for acute ischemic stroke. Stroke 2014;45:e138-50 CrossRef Medline

24. Muscedere J. Which antibiotic for hospital acquired pneumonia caused by MRSA? BMJ 2014;348:g1469 CrossRef Medline 